\title{
Optimize the Teaching of English Majors' Optional Course Via M-Learning
}

\author{
Ping Yan \\ School of Foreign Languages, \\ China West Normal University \\ Nanchong, P. R. China \\ e-mail: ms.yan@tom.com
}

\begin{abstract}
As a new learning method, M-learning has some typical characteristics, such as, easy access, individualized instruction, rich interaction and situational relevance, which can offer foreign language learning rich language inputs and interactive learning methods, and create authentic language environment. Based on the survey on the appliance of intelligent mobile phones of college students in China, this paper analyses the current situation of optional courses of English majors in Chinese university and puts forward we can make good use of M-learning to facilitate the teaching and learning of optional courses of English majors. Additionally, taking WeChat for example, this paper also refers to some practical implements via M-learning.
\end{abstract}

Keywords-Optional Course; M-learning; Implementation

\section{INTRODUCTION}

M-learning (Mobile learning) refers to access to educational information, resources and services at any time and any place with the help of a new learning method via wireless mobile communication networks and devices (such as mobile phones, notebook computers, iPad). Put simply, it is a combination of mobile communication technology and education[1]. Compared with other forms of learning methods, M-learning is figured with easy access, individualized instruction, rich interaction and situational relevance. Moreover, this learning method is far from the limitations of space and time and the constraints of content and schedule of traditional teaching. Thus the chances are that M-learning will become a new learning means in near future.

The author gets 920 essays from CNKI whose topics contain "mobile learning" mainly published after 2009. These articles mostly concentrate on the study of basic theory and domestic and foreign mobile learning environment as well as some relative education and learning theories in mobile learning context. In total, the introductory articles accumulate for $49 \%$ of the 920 essays. From the beginning of 2010 , researches on mobile learning mainly concentrate on appliance of internet technology, computer-technology, and mobile communication technology in mobile learning, and explored the feasibility of mobile learning from a technical point of view to aim at setting up a mobile learning open course platforms. Such technical articles has accumulated 268, accounting for $29 \%$. They focus on mobile system design and research, but seldom discuss the combination of mobile learning with specific subjects to optimize teaching. As a result, much attention is transferred to technology rather than effective practice of mobile learning in different teaching contexts.

\section{ANALYSIS OF OPTIONAL COURSE FOR ENGLISH MAJORS IN CHINA}

\section{A. The Properties of Optional Course for English Majors}

A foreign language is a subject with strong practicality. One must practice a lot to obtain better learning results. English majors' elective courses aim at meeting students' different levels, hobbies and requirements of emotional attitudes, developing their active thinking and bold practical skills during the language learning process, as well as enhancing their cross-cultural awareness and forming an autonomous learning ability[2]. In addition, it helps cultivate students' overall language ability, and promote their overall development. Take third year English majors' optional courses in a university of Sichuan province in China for example, it covers English language tests, American cultural history and English novels. American film and culture, English stylistics, and English poetry appreciation are open to senior students in the university. These optional courses can expand the horizons of students, enhance students' humanities accomplishment, and promote college students' English comprehensive ability from different levels. For example, English film appreciation showcases the social and cultural scene of English-speaking countries in a direct, genuine, and accurate way and spreads exotic culture, language habits, ways of thinking, life styles, values and moral norms with its rich vocabulary and vivid image, which promotes students' language skills development and cultural awareness sensitivity. Therefore such courses can play an important role to improve students' artistic accomplishment and develop their English language skills.

\section{B. Problems of Optional Course for English Majors}

However, at present, the most popular optional course has some obvious problems. First, the majority of courses are arranged in the evening or the weekends, which increases the students' and teachers' learning burden. Second, the number of students is often limited by the size of classroom, teaching 
equipment and other physical conditions. So many students have no chance to choose their favorite courses and lose the enthusiasm for optional course. Third, teaching hours of optional course are relatively short and In general there is only two-hour teaching each week. So such short learning time is utterly inadequate for language learning and language skills. Fourth, in many optional course classrooms, there are more than 100 students but only one teacher, so it is very hard for teachers to design or organize any classroom discussion students and teachers hardly have any interaction, which is not conducive to language comprehension and expression. Last but not least, the one-way evaluation method from teacher to student in optional course is still a difficult issue to solve.

\section{ANALYSIS OF M-LEARNING}

\section{A. Investigation on Students' Mobile Devices of English Majors}

In order to analyze the feasibility of mobile learning in optional courses of English majors, the author issued a questionnaire on star site with the topic of "a survey on mobile learning needs of college students based on smart mobile phones. [3]" Teachers asked the students to fill in the questionnaire. The survey data and analysis are as follows: participants in the investigation are 110 students, 110 valid questionnaires are collected and questionnaires are 100\% effective. In the survey, there are 105 students who own intelligent phones, accounting for $95.45 \%$ of the total. Among these students, 105 often surf the internet by smart phones, accounting for $100 \%$ of smart phone owners. The author thinks it is mainly due to the construction and development of campus wireless network covering classrooms, dormitories and libraries, which provides the most solid network support for students to surf the internet on the mobile phones. According to the survey, mobile phone QQ, micro-blog and WeChat, UC browser are commonly used software on mobile phone. Among them, WeChat users accounted for $80.90 \%$ of the total. This data is even 10 percentage points higher than the traditional QQ chat. WeChat was launched just a few years ago in China but won approval of many young college students. It is believed that the main reason for this is the terminal of smart phone, as the main carrier of WeChat, is well integrated with mail list, QQ friends and micro-blog friends . So it forms a multi-level communication, and friends from these three groups can communicate and closely involve. $82.73 \%$ of respondents often use smart phones to access learning-related information, and 58.18\% often use smart phones to contact teachers and friends via WeChat. At the same time, $80 \%$ of participants chose m-learning when waiting for others or before going to bed. The author thinks that it is because college students have less pressure from parents and teachers in learning and have more free time that they can make full use of spare time to have their individualized mobile learning. Meanwhile mobile learning makes learners easily access to information and foreign resources at any time and any place. In view of the survey results, the author thinks it is feasible that application of mobile learning assists optional curse teaching in college from hardware facilities perspective.

\section{B. Survey on Students' Attitude towards M-Learning}

In the survey, the author gave special attention to college students' attitudes towards M-learning. Up to $72.73 \%$ of the students think that "using smart phones for learning can assist traditional classroom learning" and $23.64 \%$ think "using smart phones for learning is very promising and smart phones can even become the main way of learning". On the frequency of using smart phones for learning, up to $97.27 \%$ of the students hold that "they will apply mobile learning occasionally". About the using time, we find that among 109 respondents, $99.09 \%$ of them believe "the most appropriate time duration of M-learning is within half an hour". Researchers at Stanford learning lab find that mobile learners are easily affected by the outside world, which makes them unable to stay concentrated for long [4]. On the advantages of using smart phone as mobile learning terminal, $64.55 \%$ agree that "mobile learning is characterized with autonomy and high selectivity, and the users can control the learning process". $84.55 \%$ of the respondents think that "smart phone for mobile learning is portable and available at any time." $76.36 \%$ assume that "mobile learning can assist them to manage their free time wisely". On the attitudes towards mobile learning of foreign language, $81.82 \%$ are convinced that "mobile learning can be done at any time and place. It's easy access for them". $62 \%$ believe that "mobile learning strengthens and promotes the daily learning effect". Other $38 \%$ insist that "mobile learning enhances the autonomy in foreign language learning and increases the interest of learning". Anyway, most of the students hold a positive and optimistic attitude to mobile learning in foreign language learning, and they are willing to apply it to their foreign language learning. Therefore, based on learners' attitudes, the application of mobile learning in optimal courses for English majors is feasible.

\section{Analysis about Teachers' Attitudes toward M-learning}

In order to understand teachers' attitudes towards Mlearning assisting optimal teaching, the author interviewed five teachers openly who taught optimal courses for students of English major. The teachers interviewed generally support the mobile learning. They believe that M-learning plays a supporting role in language learning and it is feasible to introduce M-learning in optional teaching. Besides, they hold that "the use of mobile phones and other mobile learning tools can enhance students' interest in learning English", "it allows students to achieve more autonomous language learning", "it enables students effectively participate in classroom activities and classroom discussions", "classroom teaching can effectively be extended in the aspects of time and space", "it can provide a powerful expansion of resources for students' language input", "it can be a good solution to the problem of limited classroom teaching time" and "it can better achieve interaction between the teacher and the student and among students to set up better interpersonal relationships" [5]. Accordingly, the author believes that teachers generally hold supportive attitudes toward the role of $\mathrm{M}$-learning in major elective course. 


\section{THE ADVANTAGE OF COMBINATION OF M- LEARNING WITH LANGUAGE LEARNING}

\section{A. Definition of M-Learning}

At present, there is no unified and exact definition of Mlearning. Different experts from different backgrounds gave different interpretations about M-learning. Some scholars believe that M-learning is a kind of learning activity with the help of a mobile computing device, which happens at any time and in any place. The mobile computing devices used in M-learning must be able to effectively present learning contents and provide two-way communication between teachers and learners. The definition of M-learning from the national association of committees in educational technology of colleges and universities: M-learning means that relying on relatively mature wireless mobile networks, international internet and multimedia technology, students and teachers can achieve interactive teaching activities more flexibly and conveniently, as well as the exchange of information about education, science and technology, through the use of more commonly used wireless devices currently (such as mobile phones, PDA, laptops, etc.) [6]

\section{B. The Advantages of M-learning in Learning English}

Compared with other learning forms, M-learning possesses the feature of easy access, individualized teaching, plentiful interaction and situational relevance. Mobile learning is not controlled by time and space, and there is no limit to the content or the progress, which will be a brand-new means or modes of teaching and learning in the future. What's more, based on wireless network, M-Learning has more advantages than traditional teaching model in the aspects of source tape, teachers' role, students' status, teaching evaluation and learning methods. [7]

First of all, M-learning has a strong interactive advantage. English itself is a kind of communication tool, and the active interaction between teaching and learning offers a chance and platform to practice more. Based on the network, teachers and students are able to exchange experience. The design of Mlearning can realize a good interaction module among teachers, students and machine. Such interaction can provide learners with timely help to make them engage in the learning process. Besides, it can promote the understanding and agreement between teachers and students, which helps to build a harmonious learning environment and plays a positive role in promoting the implementation of the course. Another interaction between students is also frequent in M-learning, which becomes the most typical characteristics of mobile learning and the basis for the construction of mobile learning community [8]. Interaction and resources sharing between students are also important in mobile learning which can satisfy the learner's experience sharing. And the learners, who are at the similar level of development, can also learn from each other through their communication.

Second, M-learning has the advantage of rich and available learning resources. With the rapid development of internet technology, wireless network, 3G, even $4 \mathrm{G}$ have become more and more popular, and the powerful online resources can also offer English learning more solid foundation at the same time. Accordingly, mobile learning can draw rich nutrition from these vast resources.

Third, M-learning has the characteristic of openness. Compared with traditional learning, mobile learning has more advantages. It is not limited by anywhere and anytime. As long as there is the internet, language learning will naturally take place. Foreign applied research has proved that the mobile learning has strong potential for foreign language teaching, especially in foreign language writing and hint fiction appreciation. As for the aspect of vocabulary teaching, it can be realized in sentence making of new words, word usage, as well as video dictation, summary and reviews, etc.

Fourth, M-learning has the advantage of learning autonomy. During the process of mobile learning, the information-disseminator and information-receiver exist relatively, and both of them can complete propagation behavior under virtual internet learning environment. Students are the object of teaching content, but they also have their own individual initiative in the process of learning. Thus, teachers can timely adjust teaching contents according to students' feedback. Therefore, we can regard mobile learning as a way of learning in which the center is learners. Based on individual interests, learners can choose the appropriate learning contents and use appropriate ways to learn. Learners with different personal desires tend to choose learning methods they prefer, and decide to learn or not, as well as decide the learning steps and processes by themselves. In addition, they can make their own autonomous learning evaluation and get feedback information in time. So mobile learning can be regarded as a kind of individualized learning, individuals actively construct knowledge and information processing. Compared with traditional teaching and learning, mobile learning can reflect greater democracy. Learning is no longer fettered by the traditional classroom or lashed by course schedule, and beset by teaching plan. As long as there is the subjective initiative of learners, learning will happen easily and naturally.

\section{TEACHING DESIGN OF OPTIONAL COURSE BASED ON WECHAT}

Based on the above analysis, we have understood the difficulty and problem in the English elective courses. Faced with the limited enrollment and teaching time, and the lack of interaction between teachers and students, the author attempts to put WeChat, the popular mobile learning, into elective course of English majors. The terminal of smart mobile phone as the main carrier of WeChat, which well integrates with the mobile phone mail list, QQ friends and micro-blog friends, forms a multi-level communication, so that friends from these three groups can communicate and get involved closely. The information can be transferred in diversified ways through voice, text, images, music, etc. via WeChat. In terms of the effectiveness of media, the dissemination of information via WeChat is not only immediate, but also allows the audience selective acceptance, in other words, the audience can actively select what to receive and when to receive, which is the biggest advantage of WeChat. Besides, the timely exchange of WeChat and storage function can keep the information for a long time. 
In the mobile learning model based on WeChat, teachers upload the teaching content on the public platform, and send group-messaging by the mass public account. Students can $\log$ in the teachers' public accounts. Then communication channels between the educators and the students can be constructed in this way. Students receive information and the feedback given by teachers through WeChat. So the one-onone counseling is constructed by WeChat. When teachers and students become each other's friends, they can have a direct communication too. Teachers can use the public platform to group students and send different information to different teaching groups. Since the mobile learning is in a "flexible" state, learners can learn in dispersed time, and accept small capacity of information. So it puts forward a requirement for teachers when designing mobile learning resources, they should pay attention to relatively simple prototype, develop a suitable way for audio-visual input suitable for the dispersed learning and not easily interfered by the outside world.

The WeChat based on mobile learning mode emphasizes teacher's leading role and student's central position, improving student's initiative and personal experience, training student's ability to acquire information and knowledge. Friend circle of WeChat also inspires students to explore the features of mobile learning. Although it lacks of systematic teaching, WeChat always takes the students as the learning core, the learning resources design as the key point, uses public account as mobile learning platform, and WeChat App as a tool for communication. So even under the condition of the classroom teaching, individual counseling, discussion teaching, inquiry teaching and the special website teaching and other forms of teaching activities can be carried out.

\section{CONCLUSION}

Despite advanced technology brings a bright future of problem solving, but we also need to consider that the fantastic worship of technology may bring negative effect. A common mistake we make is regarding the possibility as the fact itself, resulting in a blind optimism. Instrumental features of mobile phone determine that the cost to use mobile phone is not necessarily linked to effect of learning, only learners use properly, can really play its educational effectiveness. Based on this point, we must not fall into the idealized trap "technology is omnipotent". What's more, the advanced technology can bring about high effectiveness, but it cannot deal with learner's learning motivation. However, motivation plays a very important, even decisive role in human learning. In other words, if learners cannot be driven by their instructive motivation, efficiency of M-learning based on mobile media will be heavily discounted.

\section{REFERENCES}

[1] "Mo bile $\begin{gathered}\text { Learning", } \\ \text { Bttp://baike baidu }\end{gathered}$

2] L.Z.Li, "A Status Analyzing the Current Situation of English Selective Courses"[J], Journal of Yunnan Agricultural University, No.1, 2010, pp. 46-49.

[3] A Questionnaire Survey of Smart Phone-Based Learning Needs Analysis of College Students, http://www.sojump.com/jq/2117485.aspx
[4] M.Yi and L. Guo, “A Survey of University Students' Mobile Learning of Foreign Language" [J], Journal of Jiangxi Radio \& TV University, No.1, 2012, pp. 60-63.

[5] H.X.Liu, "The Application of Apple Mobile Devices in Language Learning”[J], Open Education Research, No.2, 2013, pp. 102-107.

[6] J.P. Zhang, "Modern Educational Technology: Theory and Application”[M], Beijing: Higher Education Press, 2006.

[7] Y.P.Lu and P.Zhi, "The Study of Foreign Language Mode Based on the Mobile Learning Terminal'[J], Modern Educational Technology, No.6, 2003, pp. 71-75.

[8] X.T.Mi, H.X.Dai and Y.M.Wang, "Design and Research of Foreign Language Learning Network based on Connectivism" $[\mathrm{J}]$, China Educational Technology, No.4, 2013,pp. 99-102. 